\title{
When Compassion Hurts: An Autoethnographic Experience of Vicarious Trauma by a Forensic Nurse
}

\author{
Sebaeng Jeanette M \\ School of Nursing, Faculty of Health Sciences, University of Free State, South Africa
}

\begin{abstract}
Caring for victims of violence includes obtaining history, examining and collecting evidentiary matter, and providing expert testimony in the court of law. In this paper, the researcher shared her own experiences as a forensic nurse on how being compassionate and listening to the stories of victims of violence and witnessing the sustained injuries led to some emotional stress which is referred to in the literature as vicarious trauma. Working every day with victims led to an altered worldview that impacted the researcher's psychological, physiological, and social being. A qualitative autoethnographic approach was explored to describe the researcher's experiences working with victims of sexual assault in a designated center within a public hospital. Personal narratives were used as a data collection method and thematic approach to analyze and describe the experiences. Although the researcher acknowledges that not every forensic nurse may suffer symptoms resulting from vicarious trauma, the shared experiences may add value to individuals who have an interest in enrolling for a clinical forensic nursing course in becoming conversant with the concept, to think of ways to handle vicarious trauma and seek interventions on time. Moreover, organizational managers may know the ordeal, forensic nurses' experience and provide the necessary support.
\end{abstract}

Keywords: Autoethnography, Compassion, Forensic nurse, Vicarious trauma.

Int J Eth Trauma Victimology (2021). DOI: 10.18099/ijetv.v7i03.9

\section{INTRODUCTION}

$\mathrm{O}$ ne of the major roles of the researcher as a forensic nurse included interviewing, gathering evidence of sexual abuse and treating any injury sustained during the assault. ${ }^{1}$ The researcher also had to provide expert testimony as deemed necessary by the court of law. During interaction and care of victims of violence, the researcher got exposed to some of the cruellest and most horrific things human beings could do. According to Newman et al. (2021), exposure to traumatic events in the workplace is known to have a psychological impact on the healthcare professionals such as anxiety, insomnia or even traumatic symptomology, referred to as vicarious trauma, a concept that the researcher was not familiar with at the time. ${ }^{2}$ It took the researcher several months of working at the trauma centre, which was specifically designated for caring for victims of violence, specifically sexual assault and rape cases, to experience life changes that included chronic changes in the researcher's perception of the world ${ }^{3}$ and how the researcher started viewing people around the community.

Despite the professional attributes and ethical behaviors of dealing with victims of violence acquired during training, the researcher realized later in life that she was suffering from vicarious trauma. Vicarious trauma has been described in the literature as the profound and unique psychological effect on psychotherapists of working with sexual violence survivors. ${ }^{4}$ According to Wies and Coy (2013), vicarious trauma symptoms are similar to those of post-traumatic stress disorder (PTSD); however, it differs in that the person with vicarious trauma has not experienced the traumatic event first-hand. ${ }^{3}$ As opposed to compassion fatigue that may be experienced as a result of a
Corresponding Author: Sebaeng Jeanette M, School of Nursing, Faculty of Health Sciences, University of Free State, South Africa, e-mail: sebaengjko@gmail.com

How to cite this article: Sebaeng JM. When Compassion Hurts: An Autoethnographic Experience of Vicarious Trauma by a Forensic Nurse. Int J Eth Trauma Victimology. 2021;7(2):44-46.

Source of support: Nil

Conflict of interest: None

Received:22/11/2021; Received in revised form: 09/12/2022;

Accepted:11/12/2021; Published:25/12/2021

deep desire to alleviate the pain or suffering of another person, ${ }^{5}$ vicarious trauma entails negative and accumulative changes that occur when one engages in an empathetic relationship with clients and develops through clients' disclosures of trauma. ${ }^{6}$

Like the researcher, most nurses may develop an interest in entering the forensic nursing field specialization without knowing the impact that the services they will be provided to victims of violence may have on their health. The objectives of this paper are therefore to:

- To share the psychological and physiological symptoms experienced by the researcher from interacting with victims of violence, specifically sexual assault and rape cases that may be mistaken for pathology.

- To share knowledge that will enable forensic nurses to understand the concept of vicarious trauma to identify the early signs and symptoms and seek interventions timeously.

- To make recommendations to countries developing forensic nursing curriculum to include vicarious traumatization in the programme. 


\section{Material and Methods}

This paper employed a qualitative autoethnographic approach. Autoethnography is of interest to the researcher because its epistemological focus enables the researcher to explore, explain, and analyse own experiences scientifically. ${ }^{7}$ Moreover, autoethnography created a platform for the researcher to place the self (auto) in a sociocultural context (ethno) and explain (graphy) it. As averred by MacMillan and Ramirez (2016), this means the researcher used their autobiographic material as the primary data. ${ }^{8}$ Although autoethnography can be written collaboratively (collaborative autoethnography), this paper presents a single author autoethnography.

\section{Data Collection}

Data collection in this paper was drawn through personal narratives and self-reflections resulting from the researcher's experience of interacting and providing care to victims of sexual assault and rape. The researcher is a forensic nurse who worked in one of the designated centres within a public hospital of South Africa referred to as Thuthuzela Care Centres. There are 54 TCCs distributed across the country and they provide comprehensive management of sexual assault victims. ${ }^{9}$ The shared experience resulted from 29 months of working with victims of gender-based violence.

\section{Ethical Considerations}

Ethics is very critical in every research and the related ethical principles must be observed at all times. Some of the ethical challenges identified in autoethnography include researcher vulnerability. ${ }^{10}$ The researcher is cognizant of what Lapadat refers to as relational ethics i.e. despite having to provide an account on own personal narratives, the researcher is not an island and that the stories shared are not wholly my own implicate relational others with whom the researcher have interacted. In this paper, no names were mentioned to anonymize those who may be implicated. Moreover, full descriptions of the cases dealt with were not provided to avoid linkages of the stories to the clients thus keeping their information confidential.

\section{Results}

\section{Experiences of Working with Trauma Victims}

Working with trauma cases directly subjected the researcher to almost the same symptoms experienced by victims of violence and was mainly psychological and physiological. On the other hand, constant exposure to trauma stories and injuries from victims changed how the researcher behaved and interacted with people in public areas. Lack of support from the organizational managers as well as failure to understand what forensic nursing work entails and its potential effects on the general health of the carer also exacerbated the situation.

It all started hardly two years after having joined this particular hospital when the management co-opted the researcher to serve in a task team to develop a strategic plan leading to opening a specialized centre for victims of violence.
The researcher accepted the delegation as a team member but was unsure of the role expectation and the contribution value with limited knowledge on the scope of the field. A formal enrolment for forensic nursing science with a university became an option for the researcher to learn more about managing violence survivors. The journey began in 2006 and the program included theoretical and practical components. The first trimester of the training was conducted within the university and mostly comprised the theoretical component. The end of the first trimester led to hospital placement for the practical component. The clinical staff and lecturers introduced us to the actual role of a forensic nurse. As part of the training, we got assigned a task whereby we identified a case, obtained history, and examined the victim alongside an experienced doctor or forensic nurse. The researcher's first case involved a gang rape of a woman who also got robbed of her valuables and stabbed in the chest with a knife. The woman got admitted from sustaining a pneumohaemothorax. The researcher followed up on the case and could not believe the lady's ordeal was going through.

During the case presentation to the lecturer six weeks later, it felt like the information was heard for the first time. The researchers disrupted the presentations, sobbing into tears from the beginning until the end. The training continued for 12 months and there were always supervisors and lecturers in the clinical setting, guiding and providing support on how to deal with different victims of violence.

\section{Going Solo as an Independent Practitioner}

The challenge began when the researcher had to practice independently. There were no trained forensic nurses, particularly in the North West Province of South Africa. The researcher worked during weekdays shifts of 07:00 am to $4: 00 \mathrm{pm}$. Care was rendered to victims of all ages, and second opinion was solicited from medical practitioners, gynecologists, and other medical specialists within the hospital as necessary. The researcher's work entailed listening to survivors' stories, examining and collecting evidentiary matter almost every day. Six months after working at this center, the researcher started experiencing persistent leftsided chest pain. A medical examination was done at different intervals during consultations by three medical practitioners at different intervals in the emergency department, whereby two performed an ECG with no sign of any pathology to the heart. The researcher was eventually diagnosed with work-related stress and referred to a staff wellness clinic for further management. As time went by, the researcher started becoming obsessed with my safety and security and my significant others. All the security measures within the researcher's means around the house were put into place. Failure of the kids to arrive home at an expected time after school will make the researcher feel not at ease, leading to a mad driving around the township searching for them. The researcher became obsessed with the safety of young girls and boys in the community and as a result, became socially irrational. 
Gender-based violence in South Africa is very high and thus demands forensic nursing service to communities. The researcher could not endure the stress associated with the service and eventually left the center. This was exacerbated by lack of support and constant exposure to trauma stories, witnessing injuries, and engaging with all stakeholders involved. However, the researcher's thoughts were constantly with the women and children who needed to be cared for. As a result, the researcher vowed to support colleagues who are currently practicing as forensic nurses. Together with forensic nurses in the country, the researcher established the South African Forensic Nursing Association (SAFNA), which aims to provide the necessary support and empowerment to practicing nurses.

\section{Discussion}

Constant exposure to trauma narratives and injuries can change the perception of an individual about self, others, and the environment. In other instances, a person may suffer from both physiological and psychological symptoms, which may temporarily or permanently affect their functioning and work productivity. Therefore, forensic nurses must learn to develop coping strategies to provide much-needed care to victims of violence.

\section{Conclusion}

The researcher entered the field of forensic nursing specialization without any idea of its envisaged impact on her health and was illiterate as far as vicarious trauma is concerned. Although the researcher is aware that individuals react differently to similar situations and that not everyone exposed to trauma stories and injuries develops symptoms, the researcher feels that forensic nurses must be conversant with the concept of vicarious trauma, which is to be accomplished through training for nurses already in practice. Vicarious trauma topics may also be included in the forensic nursing curriculum, enabling nurses to identify the symptoms at an early stage and seek assistance on time. It is also significant for practicing nurses to create platforms such as communities of practices of forensic nurses to debrief and support each other.

\section{REFERENCES}

1. Rostron, M. S., \& Furlonger, B. A preliminary investigation of vicarious traumatisation among forensic medical examiners of sexual assault. Journal of Counselling Profession. 2018; 1: 37-48. Available from

2. Newman, C., Roche, M., \& Elliott, D. Exposure to workplace trauma for forensic mental health nurses: a scoping review. International journal of nursing studies. 2021;117: 1-13.

3. Wies, J., \& Coy, K. Measuring violence: Vicarious trauma among sexual assault nurse examiners. Human Organization. 2013;72(1):23-30.

4. Barros, A. J., Teche, S. P., Padoan, C., Laskoski, P., Hauck, S., \& Eizirik, C. L. Countertransference, defense mechanisms, and vicarious trauma in work with sexual offenders. Journal of the American Academy of Psychiatry and the Law. 2020; 48(3):302-314.

5. Tabor, P. D. Vicarious traumatization: Concept analysis. Journal of Forensic Nursing. 2011;7(4):203-208. doi.101111/j.1939-3938. 2011. 01115.x.

6. Slack, D. P. (2020). Trauma and coping mechanisms exhibited by forensic science practitioners: a literature review. Forensic Science International: Synergy. 2, 310-316.

7. Naghvi A \& Salimi S. 2018. An auto ethnography of vicarious trauma and vicarious growth in the context of rehabilitation counselling. Iran Journal of Psychiatry Behavioural Science 12(4) e62687.

8. McMillan, C., \& Ramirez, H. E. Autoethnography as therapy for trauma. Women \& Therapy. 2016; 39: 432-458. Available from https://doi.org/10.1080/02703149.2016.1117278

9. Kaswa, R. (2021). The impact of the COVID-19 pandemic on healthcare service access for the victims of sexual assault. South African Family Practice, 63(1).

10. Lapadat, J. C. Ethics in autoethnography and collaborative autoethnography. Qualitative inquiry. 2017; 23(8):589-603. Available from doi 10.1177/1077800417704462 